\title{
Olfactory function in migraine both during and between attacks.
}

\author{
Michael J. Marmura \\ Thomas Jefferson University \\ Teshamae S Monteith \\ University of Miami, Department of Neurology \\ Waseem Anjum \\ Thomas Jefferson University \\ Richard L Doty \\ Smell and Taste Center, Department of Otorhinolaryngology, University of Pennsylvania \\ Sarah E Hegarty \\ Thomas Jefferson University \\ Follow this and additional works at: https://jdc.jefferson.edu/neurologyfp \\ See next page for additional authors \\ Part of the Neurology Commons \\ Let us know how access to this document benefits you
}

\section{Recommended Citation}

Marmura, Michael J.; Monteith, Teshamae S; Anjum, Waseem; Doty, Richard L; Hegarty, Sarah E; and Keith, Scott W, "Olfactory function in migraine both during and between attacks." (2014).

Department of Neurology Faculty Papers. Paper 76.

https://jdc.jefferson.edu/neurologyfp/76

This Article is brought to you for free and open access by the Jefferson Digital Commons. The Jefferson Digital Commons is a service of Thomas Jefferson University's Center for Teaching and Learning (CTL). The Commons is a showcase for Jefferson books and journals, peer-reviewed scholarly publications, unique historical collections from the University archives, and teaching tools. The Jefferson Digital Commons allows researchers and interested readers anywhere in the world to learn about and keep up to date with Jefferson scholarship. This article has been accepted for inclusion in Department of Neurology Faculty Papers by an authorized administrator of the Jefferson Digital Commons. For more information, please contact: JeffersonDigitalCommons@jefferson.edu. 
Authors

Michael J. Marmura, Teshamae S Monteith, Waseem Anjum, Richard L Doty, Sarah E Hegarty, and Scott W Keith 
Title: Olfactory acuity in episodic migraine at baseline and during attacks

Word Count (not including abstract): 2430

Abstract word count: 245

Michael J Marmura MD 1, Teshamae S. Monteith MD 2, Waseem Anjum MD 1, Richard

L Doty PhD 3, Sarah E Hegarty M.Phil 4 , Scott W Keith PhD4

1 - Thomas Jefferson University, Department of Neurology, Jefferson Headache Center, Philadelphia, PA, USA

2- University of Miami, Department of Neurology, Miami, FL USA

3- Smell \& Taste Center, Department of Otorhinolaryngology, Perelman School of Medicine, University of Pennsylvania, USA

4 - Division of Biostatistics, Department of Pharmacology and Experimental Therapeutics, Thomas Jefferson University, Philadelphia, PA, USA

\section{Disclosures:}

MJ Marmura received clinical research funding support for this project from Merck, has received honorarium for consultation from MAP pharmaceuticals, and received royalties for publications from MedLink Neurology, Cambridge and Devos Medical.

RL Doty is President and major shareholder of Sensonics, Inc., the manufacturer and distributor of olfactory and taste tests, including the odor identification test that was used in this study.

Drs. TS Montheith, W Anjum, SE Hegarty and SW Keith report no disclosures. Principal and Corresponding Author: 
Michael J Marmura MD

Thomas Jefferson University, Department of Neurology, Jefferson Headache Center

111 S 11th St \#8130 Philadelphia PA 19107

215-955-2243 Phone

215-955-2060 Fax

\section{Michael.Marmura@jefferson.edu}

Contributions to manuscript:

MJ Marmura: drafting/revising the manuscript for content; analysis or interpretation of data; patient recruitment; study concept or design; study supervision or coordination. W Anjum: drafting/revising the manuscript for content; patient recruitment; study supervision or coordination. TM Monteith: drafting/revising the manuscript for content; analysis or interpretation of data; study concept or design. RL Doty: drafting/revising the manuscript for content; analysis or interpretation of data; study concept or design. SE Hegarty, SW Keith: drafting/revising the manuscript for content; analysis or interpretation of data; statistical analysis; study concept or design. Acknowledgements: Kathleen Bradley and Rose Tausendfreundt for their help with patient recruitment and managing this study. Stephen Silberstein for assisting with study design.

This study was sponsored by the Merck Investigator Initiated Studies Program, ID \#36578. 
Introduction: Persons with migraine often report being osmophobic, both during and between acute migraine attacks. It is not clear, however, whether such reports are associated with true hypersensitivity to odors, as measured by psychophysical testing. In this case-control study we quantitatively assessed olfactory identification ability, which correlates with threshold tests of olfactory sensitivity, in patients with migraine at baseline (no headache), during migraine episodes, and after a treated attack and compared the test scores to those of matched control subjects.

Methods: Fifty episodic migraine subjects and 50 and sex- and age-matched controls without headache were tested. All completed University of Pennsylvania Smell Identification Test (UPSIT), a standardized and well-validated olfactory test.

Results: At baseline, the UPSIT scores did not differ significantly between the migraine and control study groups (median paired score difference: $-1, p=0.18$ ). During migraine attacks, a minority of migraine subjects ( 8 of 42) developed microsmia (i.e., lower test scores by at least 4 points), suggesting that, as compared to their matched controls, olfactory acuity was somewhat impaired during migraine attacks $(\mathrm{p}=0.02)$. This difference was less pronounced and not statistically significant after a successfully treated $\operatorname{attack}(\mathrm{p}=0.15)$.

\section{Discussion:}

Persons with episodic migraine were found to have similar olfactory function as age- and sex-matched controls, but a minority exhibit microsmia or hyposmia during acute attacks. The cause of this dysfunction is unknown, but could relate to autonomic symptoms, limbic system activation, or disorders of higher order sensory processing. 


\section{Introduction}

Migraine is a complex neurologic disorder related to genetic and environmental factors consisting of headache, gastrointestinal symptoms, and multiple sensory disturbances including photophobia, phonophobia, and osmophobia in the absence of a causative secondary disorder. Hypersensitivity to sensory stimuli such as light and sound are classical diagnostic features of migraine [1], although migraineurs are also more likely to be bothered by odors than other persons. In fact, osmophobia may be a more specific symptom in differentiating migraine from other headache disorders $[2,3]$, and including it as a diagnostic criterion may increase the sensitivity for accurately diagnosing migraine in populations where photophobia is less common [4]. Osmophobia is most prominent during acute migraine attacks, but discomfort may persist interictally in a subset of migraineurs [5].

Olfactory impairment is a common symptom found in a number of neurologic disorders, such as Parkinson disease, schizophrenia and myasthenia gravis, possibly due to degeneration and/or dysmodulation of dopaminergic, serotonergic and cholinergic systems [6]. Multiple studies have confirmed that migraine subjects are bothered by odors, especially noxious stimuli [7,8], and that odors may precipitate attacks. One $\mathrm{H}_{2} \mathrm{O}-$ PET study showed abnormal cerebral activation patterns during olfactory stimulation in migraineurs with olfactory hypersensitivity [9]. The ability of persons with migraine to detect and discriminate odors, as determined by standardized olfactory testing, is less clear. In one study, a large number of migraine subjects had poor olfactory acuity [10], as measured by olfactory thresholds, and in another migraineurs had increased odor detection [11]. A more recent study of episodic migraine subject found that their 
olfactory acuity was normal [5]. The effect of a migraine attack on olfactory ability during and after treated attacks is also unclear.

The objective of this study was to examine olfactory acuity in episodic migraine subjects as compared with age and sex-matched controls, using a reliable and well-validated test of olfaction. We also evaluated the effect of migraine on olfaction - both during and after a treated attack.

\section{Methods}

Formal approval of this study was obtained from the Institutional Review Board at Thomas Jefferson University. Subjects ranging in age from 18 to 65 were recruited from our clinic and the surrounding community who were diagnosed with episodic migraine, as defined by the International Classification of Headache disorders $2^{\text {nd }}$ edition. We excluded subjects or controls with a history of significant headache trauma, nasal or sinus disease, neurologic disorders such as Parkinson disease, dementia, or multiple sclerosis. Persons who used medications that could influence smell function, such as anticonvulsants or opioids, barbiturates or neuroleptics - drugs often used to treat attacks - were excluded from consideration. Subjects were allowed to use simple or combination analgesics such as non-steroidal anti-inflammatory medications, including those with caffeine, and migraine-specific medications such as triptans. To ensure that we could determine the effect of a treated migraine on olfaction, we also excluded subjects which generally could not successfully treat migraines with medication. Due to the effect of gender and age on olfactory function [13], each subject was paired with a sex- and agematched (from -2 to 2 years) control without disabling headache or migraine. For the 
purposes of this study, controls were required to have a Migraine Disability Scale (MIDAS) score of zero. We did not specifically exclude persons with a family history of migraine.

During the first visit we administrated a focused questionnaire to all participants to obtain basic demographic and medical history information. We inquired as to whether odors caused them to develop headaches and whether any of five specific odors (perfume, paint, new carpet, gasoline, pesticides) were bothersome. Both the subjects and the controls completed a validated questionnaire for allodynia [14]. The initial recruitment began June 2010 and final kits were received in October 2011.

To determine olfactory function, all subjects completed the University of Pennsylvania Smell Identification Test (UPSIT), a well-validated and standardized 40-item forced choice olfactory test that is useful in detecting subtle olfactory deficits $(12,13)$. This test is more reliable, yet highly correlated, with traditional olfactory threshold tests. [15] There are a total of 40 odorants, with four booklets each containing ten odorants. The stimuli are embedded in "scratch and sniff" microcapsules at the bottom of each page. This inexpensive test is widely used clinically, and has been translated into 14 foreign languages.

The UPSIT was administered at the time of their first visit, when the subjects received instructions on how to perform the test at home. After the initial visit, subjects took the UPSIT again at home or in the office during an acute migraine attack and completed a short clinical survey about their symptoms during the attacks, including severity, location, and aura, if present. They also completed the UPSIT a third time after a typical migraine with successful treatment (either mild or no pain), at least 2 hours after the 
attack. Based on previous studies using UPSIT to determine olfaction in various neurodegenerative disorders, and assuming a true difference between the mean UPSIT scores of 3 units, we determined that with 50 subjects there would be a $93 \%$ probability that the study will detect a statistically significant difference at a two-sided 5 percent significance level. We instructed 25 subjects to take the UPSIT at home during migraine, and to complete the final UPSIT after a treated attack. The other 25 subjects took the UPSIT after a treated attack first, then the final UPSIT during migraine. Controls repeated the UPSIT after the initial visit at least 2 weeks after the initial visit, and again at least another 2 weeks later. If subjects or controls completed the UPSIT at home, it was returned to our office in person or by mail.

Data from the migraine patients and age/sex matched controls were analyzed to determine the association between migraine and olfactory acuity. The baseline characteristics and scores between matched controls and migraine patients were paired and then compared. The paired data were skewed for UPSIT scores and other variables. To address this and test for significant differences between the migraine and control groups while accounting for the correlation within matched pairs, we applied the Wilcoxon Signed-Rank test of match-paired differences for continuous variables and McNemar's test of discordant match-paired 2-level responses (or the more general StuartMaxwell test of discordant match-paired multi-level responses) for categorical variables. For all tests, a significance level of $\alpha=0.05$ was used. We accounted for missing data (subjects or controls who didn't return UPSIT kits) by comparing data with their matched pairs.

\section{Results}


Both the migraine and the control groups included 50 subjects who are matched by age and sex. (Table 1.) There were no significant differences between the groups with respect to distributions of age, sex, height, weight or BMI, although more subjects were white race $(76 \%$ vs. $66 \%$ white in migraineurs vs. controls, $\mathrm{p}=0.36)$. Allodynia was highly associated with migraine ( $92 \%$ subjects vs. $14 \%$ controls, $\mathrm{p}<0.01)$. Of the migraine subjects, about $51 \%$ reported aura with visual aura being the most common and the majority (70\%) experienced non-migraine headaches as well (Table 2). The majority of subjects (36/50 72\%) reported a history of migraine of at least 10 years.

Of those subjects who experience migraines, $32(65 \%)$ indicated that they found odors to be bothersome, while only $7(15 \%)$ of the controls did, demonstrating a significant association between group (migraine or control) and sensitivity to odors (Table 1). In terms of the matched pairs, 18 of $45(40 \%)$ had responses which agreed while $27(60 \%)$ had differing responses. Of those 27 responses, 25 (93\%) were migraine subjects who found odors bothersome and controls who did not. This discordance strongly indicated a significant association between migraine and sensitivity to odors $(\mathrm{p}<0.01)$.

The two groups had similar olfactory acuity at baseline, but the distribution of the matchpaired differences was skewed in the positive direction (Figure 1). At the time of the initial baseline visit, migraine subjects had a median UPSIT score of 36 (between attacks), while the controls had a median score of 37 . The median match-paired difference of -1 did not differ significantly from zero $(\mathrm{p}=0.18)$. Forty-two subjects completed the UPSIT during acute migraine and 40 completed the UPSIT after a treated migraine. Of the age-sex matched controls, 3 completed the UPSIT once after the initial visit and the other 47 completed both follow-up tests. 
Although the majority of migraine subjects had similar scores during migraine as in the initial visit (+/- 2 points), a minority had clinically significant decreases in acuity with 8 (19\%) scoring 4 or more points worse during acute migraine. Regardless, during their migraine attacks, the median UPSIT score for migraine subjects was still 36 as compared to 36 for controls at their second test; however, the median match-paired difference of -1 was statistically significant $(\mathrm{p}=0.02)$. This suggested that olfactory acuity during migraine was significantly impaired. After being treated, the median UPSIT of the migraineurs was again 36 compared to the median score of 37 among their matched controls at their third test. The median paired difference of -1 was not significantly different from zero $(\mathrm{p}=0.15)$. The histograms in Figure 2 present a visual distributional summary of changes in UPSIT test scores from baseline during attack (panel A.) and after successful treatment of attack (panel B.) for the migraine group. Considering a difference of three or more points on UPSIT to be clinically significant, thirteen migraine subjects had a decrease in UPSIT scores between baseline and during attacks of 3 points or greater, compared with 3 subjects after a treated attack. One patient had an increase in UPSIT of 4 points after a treated migraine, and no subject had an increase of greater than 3 points during migraine. Of the thirteen patients with clinically significantly lower scores during migraine, 12 reported allodynia during migraine, 8 had migraine with aura, 10 were female, and 9 reported a history of migraine greater than 10 years.

\section{Discussion}

The results of this study suggest that the majority of patients with episodic migraine have normal olfactory function. This agrees with the studies of Saisu et al [5] and Hirsch [10] 
and supports the idea that migraine differs from neurodegenerative disorders such as Parkinson disease. However, a subgroup of our migraine subjects appeared to have experienced impairment during acute migraine, especially before successful treatment. This finding is similar to the 1992 study of Hirsch, which predates the classification of episodic and chronic migraine, in which $18 \%$ of migraine subjects were hyposmic or anosmic based on Pyridine odor threshold testing. The clinical and demographic characteristics of our migraine subjects who had significant olfactory impairment were not significantly different than those who did not in terms of allodynia, duration of disease, sex or age, although there was a trend for greater impairment in those with aura. The effect of migraine on olfaction was relatively modest in comparison to the olfactory dysfunction of neurodegenerative disorders [16] and other neurological disorders such as myasthenia gravis [17]. In a recent study of myasthenia gravis, 27 MG subjects exhibited a robust loss of olfaction relative to 27 matched controls. It is unclear if the decreased UPSIT scores in our subgroup of migraine subjects have clinical relevance. Our suggestion would be to test olfaction in patients with clinical symptoms of olfactory difficulties, especially those with a history of previous serious viral illness, head trauma or neurodegenerative disease. It should be noted that the subjects in this study were generally fairly healthy with treatable migraine attacks. In a separate study, we plan to examine subjects with chronic migraine including those without significant headache-free time.

Our results confirmed several previous studies which confirm that persons with migraine report experiencing hypersensitivity to bothersome odors. The UPSIT is not a measure of osmophobia , is designed to be well-tolerated and did not trigger migraine attacks in this 
study. However, no subject in our study exhibited UPSIT scores that would suggest increased olfactory sensitivity during migraine (with an increase of more than 3 points on UPSIT). Although some persons with migraine may be more sensitive to odors even outside of attacks, our findings are in disaccord with those of Snyder and Drummond [11] who found migraineurs to have hyperosmia. However, their test procedures differed from ours. They studied 20 migraine subjects and 21 controls using odor detection thresholds for acetone and vanillin. Acetone is a strong trigeminal stimulant and therefore is not a good measure of olfaction, per se. [18] Our findings are in agreement with the general notion that true hyperosmia is rare, regardless of the diseases involved. [19]. Taken together, olfactory hypersensitivity is more likely a perceptual distortion as opposed to one of increased threshold sensory function both interictally and during acute attacks. Persons with a sense of hyperacute odor detection usually do not have superior olfactory abilities. Pregnancy, for example, is not associated with hyperosmia. [20] Multiple factors influence olfaction including anatomic, genetic, and sensory processing differences. Changes in autonomic function are one possible cause of worsening olfaction during acute migraine. The sphenopalantine ganglion supplies autonomic projections to the nose. Increases in parasympathetic tone, which can manifest as tearing, swelling or congestion during migraine, is associated with engorgement of nasal turbinates [21]. Fluctuations in nasal engorgement are an overall indicator of autonomic tone [22] and correlate with measures such as rapid-eye movement sleep patterns [23] and cognitive abilities [24]. Allergic disorders are more common in persons with migraine and immunotherapy may be helpful to reduce migraine severity in younger patients [25]. It is 
possible that simple changes in autonomic tone during migraine could affect performance on the UPSIT.

A more interesting potential explanation is that migraine affects areas in the brain which cause difficulty in perceiving odors when impaired. Pain-sensitive neurons from the thalamus project widely to multiple cortical regions, including the primary somatosensory cortex, the parietal association cortex, and the primary and secondary visual cortices. This suggests a mechanism for cortical dysfunction in migraine other than cortical spreading depression [26]. A recent functional MRI study found deficient habituation in the trigemino-nociceptive pathway, but not in the olfactory system suggesting the possibility that a thalamo-cortical network may be an important aspect of migraine as opposed to a single neuronal modulator. [27] Migraine is associated with activation of the amygdala and limbic system during acute attacks in a way similar to other pain disorders. The amygdala is highly involved in both odor intensity [28] and odor memory [29]. Since activation of the limbic system is a hallmark of pain disorders, it is possible that these changes may not be unique to migraine and olfactory abilities in other persons with episodic pain disorders remains unclear. A minority of persons with migraine can experience olfactory hallucinations before or during headache, which usually involves a very specific and bothersome odor [30].

Olfactory problems in neurodegenerative diseases involve injury to dopaminergic, cholinergic, serotonergic, and noradrenergic systems, microglial activation and inflammation [6]. Although our subjects generally had normal olfaction at baseline, the development of hyposmia during attacks may indicate abnormal brain functioning, perhaps at the level of the basal ganglia or higher cortical structures [31]. Many common 
migraine premonitory symptoms, such as hunger or yawning, are also thought to be related to dopamine and linked to the hypothalamus [32]. 


\section{References:}

1. Headache Classification Committee, Olesen J, Bousser MG, Diener HC, et al. New appendix criteria open for a broader concept of chronic migraine.

Cephalalgia. 2006 Jun;26(6):742-6.

2. Corletto E, Dal Zotto L, Resos A, et al. Cephalalgia. Osmophobia in juvenile primary headaches. Cephalalgia 2008 Aug;28(8):825-31

3. Vingen JV, Sand T, Stovner LJ. Sensitivity to various stimuli in primary headaches: a questionnaire study. Headache. 1999 Sep;39(8):552-8.

4. Wang YF, Fuh JL, Chen SP, Wu JC, Wang SJ. Clinical correlates and diagnostic utility of osmophobia in migraine. Cephalalgia. 2012 Dec;32(16):1180-8.

5. Saisu A, Tatsumoto M, Hoshiyama E, Aiba S, Hirata K. Evaluation of olfaction in patients with migraine using an odour stick identification test. Cephalalgia. 2011 Jul;31(9):1023-8.

6. Doty RL. Olfaction in Parkinson's disease and related disorders. Neurobiol Dis. 2012 Jun;46(3):527-52.

7. Sjöstrand C, Savic I, Laudon-Meyer E, Hillert L, Lodin K, Waldenlind E. Migraine and olfactory stimuli. Curr Pain Headache Rep. 2010 Jun;14(3):244-51.

8. Kelman L. Osmophobia and taste abnormality in migraineurs: a tertiary care study. Headache. 2004 Nov-Dec;44(10):1019-23.

9. Demarquay, G. Royet, JP, Mick, G and Ryvlin, P. Olfactory hypersensitivity in Migraineurs: a $\mathrm{H}_{2} \mathrm{O}-\mathrm{PET}$ study. Cephalalgia 2008; 28:1069-1080.

10. Hirsch AR. Olfaction in migraineurs. Headache. 1992; 32:233-236.

11. Snyder, RD, Drummond, PD. Olfaction in Migraine. Cephalalgia 1997;17:729-32. 
12. Doty RL, Shaman P, Dann M. Development of the University of Pennsylvania Smell Identification Test: a standardized microencapsulated test of olfactory function. Physiol Behav. 1984 Mar;32(3):489-502

13. Doty RL, Shaman P, Applebaum SL, Giberson R, Siksorski L, Rosenberg L. Smell identification ability: changes with age. Science. 1984 Dec 21;226(4681):1441-3.

14. Jakubowski M, Silberstein S, Ashkenazi A, Burstein R. Can allodynic migraine patients be identified interictally using a questionnaire? Neurology. 2005 Nov 8;65(9):1419-22.

15. Doty RL, McKeown DA, Lee WW, Shaman P. A study of the test-retest reliability of ten olfactory tests. Chem Senses. 1995 Dec;20(6):645-56.

16. Mesholam RI, Moberg PJ, Mahr RN, Doty RL. Olfaction in neurodegenerative disease: a meta-analysis of olfactory functioning in Alzheimer's and Parkinson's diseases. Arch Neurol. 1998 Jan;55(1):84-90.

17. Leon-Sarmiento FE, Bayona EA, Bayona-Prieto J, Osman A, Doty RL. Profound olfactory dysfunction in myasthenia gravis. PLoS One. 2012;7(10):e45544.

18. Doty RL, Brugger WE, Jurs PC, Orndorff MA, Snyder PJ, Lowry LD. Intranasal trigeminal stimulation from odorous volatiles: psychometric responses from anosmic and normal humans. Physiol Behav. 1978 Feb;20(2):175-85

19. The olfactory system and its disorders. Doty RL. Semin Neurol. 2009 Feb;29(1):74-81. 
20. Laska M, Koch B, Heid B, Hudson R. Failure to demonstrate systematic changes in olfactory perception in the course of pregnancy: a longitudinal study. Chem Senses. 1996 Oct;21(5):567-71.

21. Hirsch AR. Olfaction in migraine. Cephalalgia. 1998 Jul-Aug;18(6):360.

22. Jones $\mathrm{N}$. The nose and paranasal sinuses physiology and anatomy. Adv Drug Deliv Rev. 2001 Sep 23;51(1-3):5-19

23. Werntz DA, Bickford RG, Bloom FE, Shannahoff-Khalsa DS. Alternating cerebral hemispheric activity and the lateralization of autonomic nervous function. Hum Neurobiol. 1983;2(1):39-43.

24. Goldstein L, Stoltzfus NW, Gardocki JF. Changes in interhemispheric amplitude relationships in the EEG during sleep. Physiol Behav. 1972 May;8(5):811-5.

25. Klein R, Pilon D, Prosser S, Shannahoff-Khalsa D. Nasal airflow asymmetries and human performance. Biol Psychol. 1986 Oct;23(2):127-37.

26. Martin VT, Taylor F, Gebhardt B, et al. Allergy and immunotherapy: are they related to migraine headache? Headache. 2011 Jan;51(1):8-20.

27. Stankewitz A, Schulz E, May A. Neuronal correlates of impaired habituation in response to repeated trigemino-nociceptive but not to olfactory input in migraineurs: An fMRI study. Cephalalgia. 2012 Dec 10.

27. Noseda R, Kainz V, Jakubowski M, et al. A neural mechanism for exacerbation of headache by light. Nat Neurosci. 2010 Feb;13(2):239-45.

28. Anderson AK, Christoff K, Stappen I, Panitz D, Ghahremani DG, Glover G, Gabrieli JD, Sobel N. Dissociated neural representations of intensity and valence in human olfaction. Nat Neurosci. 2003 Feb;6(2):196-202. 
29. Buchanan TW, Tranel D, Adolphs R. A specific role for the human amygdala in olfactory memory. Learn Mem. 2003 Sep-Oct;10(5):319-25.

30. Coleman ER, Grosberg BM, Robbins MS. Olfactory hallucinations in primary headache disorders: case series and literature review. Cephalalgia. 2011 Oct;31(14):1477-89.

31. Borsook D, Upadhyay J, Chudler EH, Becerra L. A key role of the basal ganglia in pain and analgesia--insights gained through human functional imaging. Mol Pain. 2010 May 13;6:27

32. Kelman L. The premonitory symptoms (prodrome): a tertiary care study of 893 migraineurs. Headache. 2004 Oct;44(9):865-72. 
Table 1. Descriptive summary of study group characteristics.

\begin{tabular}{|c|c|c|c|}
\hline & Migraine & Control & \\
\hline & $\mathbf{n}=\mathbf{5 0}$ & $\mathbf{n}=\mathbf{5 0}$ & $\mathbf{p}$ \\
\hline Age, n (\%) & & & 0.99 \\
\hline$<30$ & $21(42)$ & $20(40)$ & \\
\hline $30-39$ & $12(24)$ & $12(24)$ & \\
\hline $40-49$ & $12(24)$ & $12(24)$ & \\
\hline $50+$ & $5(10)$ & $6(12)$ & \\
\hline Sex, female, n (\%) & $37(74)$ & $36(72)$ & 0.99 \\
\hline Race, n (\%) & & & 0.36 \\
\hline White & $38(76)$ & $33(66)$ & \\
\hline Black & $11(22)$ & $6(12)$ & \\
\hline Asian & $1(2)$ & $5(10)$ & \\
\hline Hispanic & $0(0)$ & $4(8)$ & \\
\hline Others & $0(0)$ & $2(4)$ & \\
\hline Height (in.), n (\%) & & & 0.93 \\
\hline$<66$ & $24(48)$ & $24(48)$ & \\
\hline $66-71$ & $21(42)$ & $20(40)$ & \\
\hline $72+$ & $5(10)$ & $6(12)$ & \\
\hline Weight (lbs.), n (\%) & & & 0.98 \\
\hline $100-149$ & $18(36)$ & $19(38)$ & \\
\hline $150-199$ & $23(46)$ & $22(44)$ & \\
\hline
\end{tabular}




\begin{tabular}{cccc}
\hline BMI, n (\%) & $9(18)$ & $9(18)$ & \\
Normal (<25) & & & 0.09 \\
Overweight (25-30) & $21(42)$ & $12(24)$ & \\
Obese (30+) & $11(22)$ & $10(20)$ & \\
Allodynia, n $(\%)$ & $46(92)$ & $6(14)$ & $<0.01$ \\
$>\mathbf{1}$ odors bothersome, $\mathrm{n}(\%)$ & $32(65)$ & $7(15)$ & $<0.01$ \\
\hline
\end{tabular}

BMI: body mass index $\left(\mathrm{kg} / \mathrm{m}^{2}\right)$ 
Table 2. Descriptive summary of migraine patient characteristics $(n=50)$.

\begin{tabular}{ll}
\hline Age at onset, mean \pm SD & $18.8 \pm 10.4$ \\
Age at onset, $n(\%)$ & \\
$<10$ & $6(13)$ \\
$10-19$ & $23(48)$ \\
$20-29$ & $9(19)$ \\
$30+$ & $10(21)$ \\
Aura, $n(\%)$ & $25(51)$ \\
Aura Type*, $\mathrm{n}(\%)$ & \\
None & $26(52)$ \\
Blind spots & $1(2)$ \\
Confused & $1(2)$ \\
Sensory & $6(12)$ \\
Visual & $21(42)$ \\
Motor & $2(4)$
\end{tabular}

Non-Migraine HA, n (\%) 35 (70)

SD: standard deviation; HA: headache; * Multiple choices are possible so percentages may not add up to 100 . 
Table 3. Summary of UPSIT scores.

\begin{tabular}{|c|c|c|c|c|}
\hline & & & Paired & \\
\hline & Migraine & Control & Difference & $\mathbf{p}^{*}$ \\
\hline Interictal/Baseline, Median & 36 & 37 & -1 & 0.18 \\
\hline Min-Max & $30-40$ & $30-40$ & $-6-8$ & \\
\hline mean $\pm \mathrm{SD}$ & $36.1 \pm 2.5$ & $36.6 \pm 2.6$ & $-0.48 \pm 3.04$ & \\
\hline During Attack $/ 2^{\text {nd }}$ Test, Median & 36 & 36 & -1 & 0.02 \\
\hline Min-Max & $27-40$ & $25-40$ & $-13-10$ & \\
\hline mean $\pm \mathrm{SD}$ & $35.0 \pm 3.2$ & $35.9 \pm 3.0$ & $-1.29 \pm 4.13$ & \\
\hline After Attack $/ 3^{\text {rd }}$ Test, Median & 36 & 37 & -1 & 0.15 \\
\hline Min-Max & $22-40$ & $29-40$ & $-5-10$ & \\
\hline mean $\pm \mathrm{SD}$ & $35.6 \pm 3.2$ & $36.2 \pm 2.8$ & $-0.55 \pm 3.27$ & \\
\hline
\end{tabular}


Figure 1. Difference in baseline olfactory acuity (UPSIT scores) between migraine patient and matched control pairs.

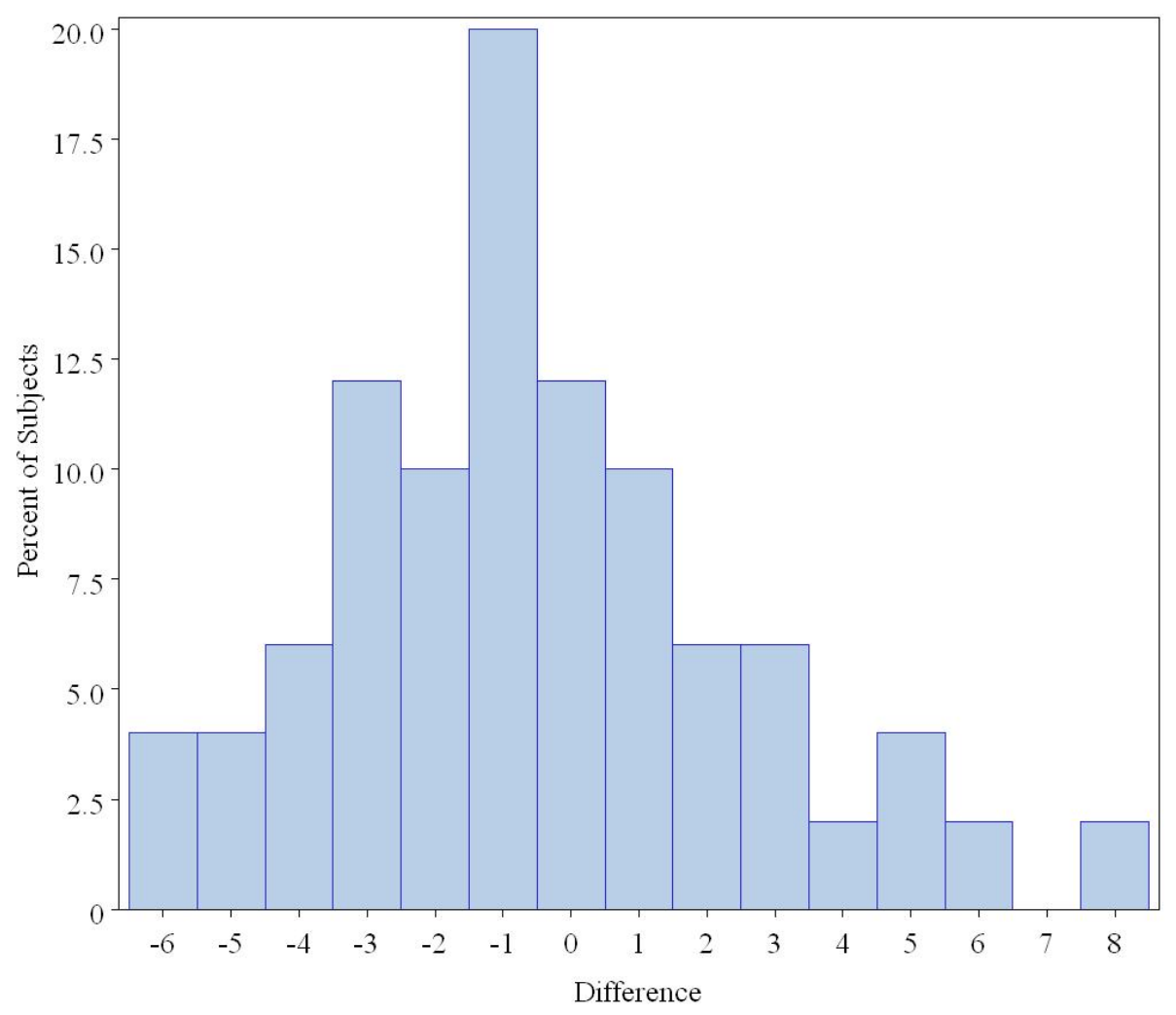


Figure 2. Histograms of changes in migraine group UPSIT test scores from baseline during migraine attack (panel A.) and after attack (panel B.).

A.

Change in test score (During Migraine - Baseline)

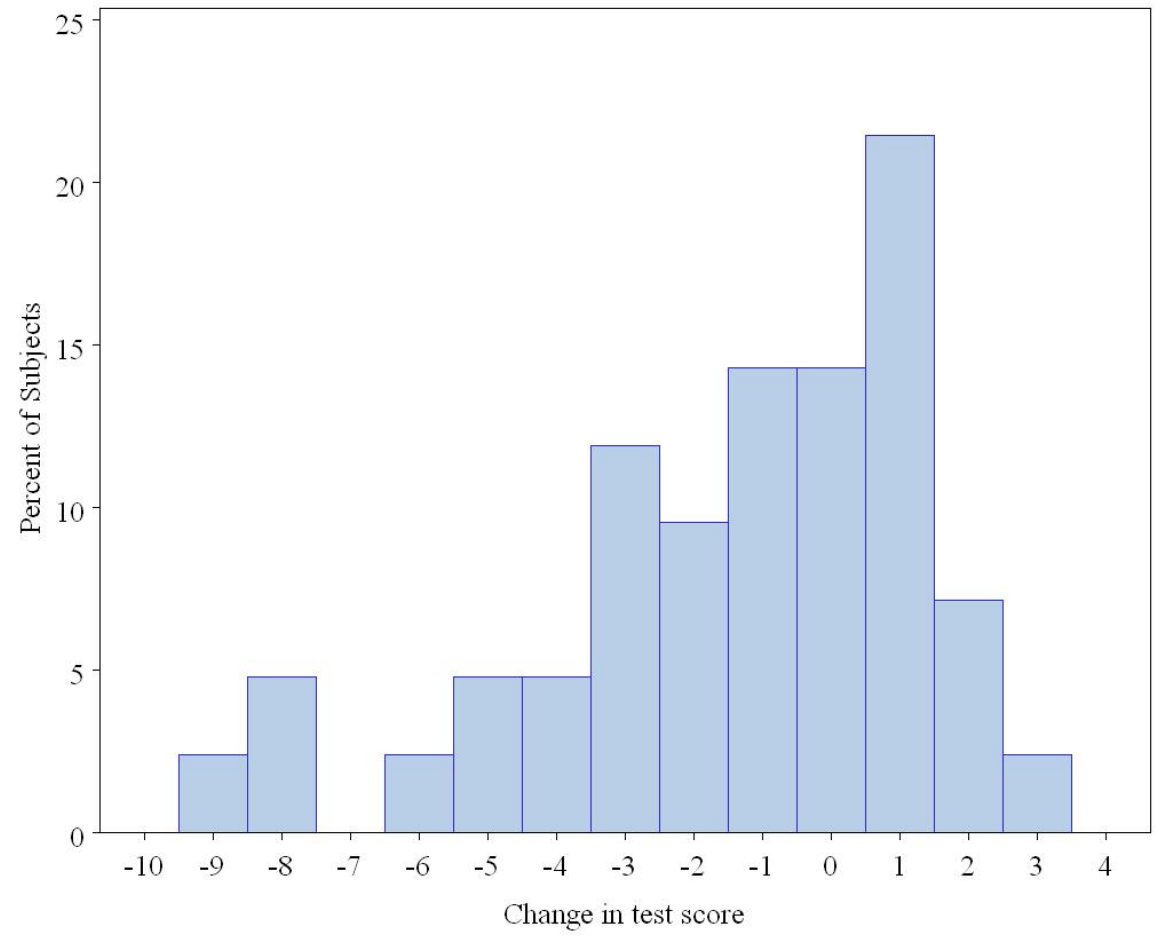

B.

Change in test score (After Migraine - Baseline)

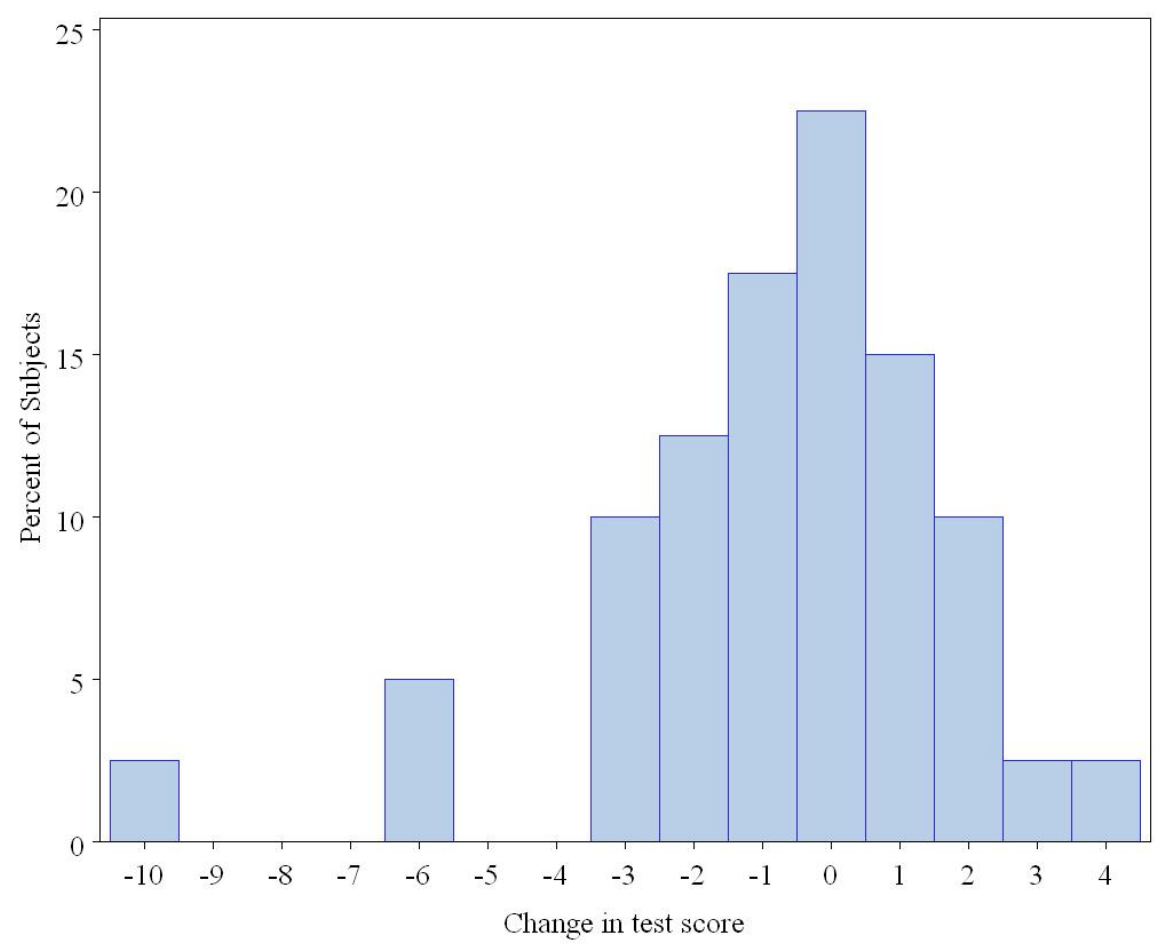


